\title{
Genetic Variation and Virulence on Lr26 in Puccinia triticina
}

\author{
E. Kosman, E. Pardes, Y. Anikster, J. Manisterski, P. Ben Yehuda, L. J. Szabo, and A. Sharon
}

First, third, fourth, fifth, and seventh authors: Institute for Cereal Crops Improvement, and second, third, and seventh authors: The Department of Plant Sciences, Tel Aviv University, Tel Aviv 69978, Israel; and sixth author: Cereal Disease Laboratory, Agricultural Research Service, U.S. Department of Agriculture, St. Paul, MN 55108.

Accepted for publication 23 January 2004.

\begin{abstract}
Kosman, E., Pardes, E., Anikster, Y., Manisterski, J., Ben Yehuda, P., Szabo, L. J., and Sharon, A. 2004. Genetic variation and virulence on Lr26 in Puccinia triticina. Phytopathology 94:632-640.

The genetic relationships between isolates of Puccinia triticina virulent on wheat with the $L r 26$ resistance gene were studied. The diversity within and between isolates of $P$. triticina from Israel, Europe, and the United States was determined by virulence on near-isogenic Thatcher lines and by random amplified polymorphic DNA. According to the molecular markers, isolates that were virulent on $\operatorname{Lr} 26$ had diversity levels similar to

of isolates virulent and avirulent on $\operatorname{Lr} 26$ varied and were unrelated to the Lr26 virulence phenotype. Cluster analysis suggested four groups, three of which were closely associated with the geographical origin of the isolates-Israel, the United States, and Europe. All four groups included both Lr26 virulent and avirulent pathotypes. The results showed that Lr26 virulent rust pathotypes are as genetically dissimilar as the rest of the population. The cluster analysis showed that the rust population in Israel includes at least two different subpopulations, both of which contain Lr26 virulent and $\mathrm{Lr} 26$ avirulent isolates.
\end{abstract} those of Lr26 nonpathogenic isolates. Distances between subpopulations

Leaf rust of wheat is caused by Puccinia triticina Eriks., a fungus that is widespread throughout the world and accounts for major yield losses each year $(1,25,26)$. Epidemiology of the disease is largely affected by (i) dispersal of the fungus over long distances through wind transmission of the asexual urediniospores (21) and (ii) ability of local rust populations to match the leaf rust $(\mathrm{Lr})$ resistance genes in wheat cultivars grown in these areas. The sexual stage of $P$. triticina occurs on the aecial (alternate) host Thalictrum speciosissimum, which grows only in southern Europe. Due to lack of the aecial host, sexual reproduction in nature is very rare, and in practice, $P$. triticina reproduces asexually, although isolates of $P$. triticina have retained the capacity of sexual reproduction (1). As a result, $P$. triticina populations tend to clonality, and differences in the virulence pattern among populations may be indicative of separate epidemiological zones. The current division of $P$. triticina into epidemiological zones has been derived from the global and regional wind patterns and is based on the assessment of virulence polymorphism in rust populations $(23,31)$. In addition, the genetic background of local wheat populations influences the composition of virulence phenotypes in a given rust population $(4,8,30)$.

Resistance to leaf rust is conferred by single dominant genes that are designated $L r$ genes (26). Over 40 such genes are currently known and used in wheat breeding programs (17). Appearance of virulent rust isolates often occurs soon after the introduction of a new $L r$ gene is widespread, and is well documented $(15,30)$. This phenomenon can be explained in several ways, e.g., by introduction of new races, new mutation, or by host selection $(4,8,9,30)$. Yet, the precise mechanism by which new rust pathotypes evolve and the dynamics of the build up of virulent populations are only partly understood. The appearance of $P$. triticina

Corresponding author: A. Sharon; E-mail address: amirsh@tauex.tau.ac.il

Publication no. P-2004-0405-02R

(c) 2004 The American Phytopathological Society
Additional keywords: Kosman index, rust virulence genes. pathotypes with virulence on $\operatorname{Lr} 26\left(\operatorname{Lr} 26^{+}\right)$and their widespread distribution in local populations worldwide provide an example for the dynamics of this process. The source of the $L r 26$ resistance is hybrid derivatives of cultivated wheat and rye cv. Petkus with a chromosomal translocation IB/IR, which were produced in the 1930s in Germany $(7,27)$. The complete resistance against leaf rust (as well as resistance to stripe and stem rusts and to powdery mildew) that was conferred by this translocation has made it highly popular among breeders. Commercial wheat cultivars with the Lr26 gene were introduced in the 1950s and over 400 wheat cultivars that carry the IB/IR translocation have been produced over the years. $P$. triticina isolates that are virulent on Lr26 were first reported in the 1960s (1). Since then, a steady increase in the level of Lr26 virulent isolates has been recorded. By the late 1980s and early 1990s, Lr26 ${ }^{+}$pathotypes were dominant in many locations. No clear correlation was noted between the level of $\mathrm{Lr}^{2} 6^{+}$and the presence of wheat cultivars that carry the $\operatorname{Lr} 26$ resistance locus. In the United States, this race was reported for the first time in 1986 at a rate of $1 \%$, and increased to $46 \%$ of the isolates, while most of the wheat cultivars grown in this region did not contain the Lr26 resistance (15). Similar findings have been reported from Israel (5).

Leaf rust is one of the most widespread diseases of wheat in Israel. The current paradigm suggests that new isolates are introduced every year by airborne urediniospores that arrive at the end of the winter (March to April) and infect wheat fields. The origin of the inoculum is unclear (5). The first report of $\mathrm{Lr}^{2} 6^{+}$isolates in Israel was in 1988 from wild wheat (5). According to a rust survey from 1992 to 1993 , only $2.5 \%$ of the rust isolates in Israel were virulent on $L r 26$. This number increased steadily during the last decade, reaching 50\% in 1997 (16). It is noteworthy that the wheat cultivars used in Israel do not contain the Lr26 resistance locus.

In this work, we compared the genetic diversity in $\mathrm{Lr}^{2} 6^{+}$and Lr26- isolates using molecular and virulence markers. Our research objective was to determine whether $\operatorname{Lr} 26^{+}$isolates form a distinct subpopulation (i.e., a cluster) or whether they are genetically similar to the general population. 


\section{MATERIALS AND METHODS}

Isolates. $P$. triticina isolates used in this study were from Israel, the United States, and Europe. Details of location and dates of isolation are presented in Table 1. Israeli isolates were from 1993 to 1997 virulence surveys and include isolates from the northern and southern parts of Israel. The European and U.S. isolates were obtained from several locations that represent a wide geographical region in each continent. A total of 60 isolates tested for virulence phenotype and random amplified polymorphism DNA (RAPD) markers were analyzed. There were 20 isolates from Israel, 10 virulent $\left(\operatorname{Lr} 26^{+}\right)$and 10 avirulent $\left(\operatorname{Lr} 26^{-}\right)$. These isolates were randomly chosen from the isolate collection of the Institute for Cereal Crops Improvement (Tel Aviv University) and included isolates from around the country as specified in Table 1. Another 18 isolates were from three places in the United States, 8 of which were $\mathrm{Lr}_{2} 6^{+}$and 10 that were $\mathrm{Lr} 26^{-}$. The European isolates included $16 \mathrm{Lr}^{2} 6^{+}$isolates (seven isolates each from the Czech Republic and Germany and one isolate each from Poland and Hungary) and 6 Lr26- isolates all from Switzerland.

Single uredinia of all isolates were increased in the greenhouse on seedlings of susceptible wheat cv. Thatcher. The plants were grown in $10-\mathrm{cm}$ pots treated with $0.1 \%$ maleic hydrazide to enhance sporulation. Pots were separated with plastic cylinders to ensure the purity of the cultures. Spores were harvested with a hand vacuum cyclone and stored in glass tubes at $4^{\circ} \mathrm{C}, 35 \%$ relative humidity, or in gelatine at $-70^{\circ} \mathrm{C}$.

Virulence phenotype. Single-uredinial isolates were tested for virulence on 17 Thatcher wheat differential lines (17) that are near-isogenic for the leaf rust $(L r)$ resistance genes: $L r l$ (RL6003); Lr2a (RL6016); Lr2c (RL6047); Lr3a (RL6002); Lr9 (RL6010); Lr16 (RL6005) Lr24 (RL6064); Lr26 (RL6078); Lr3Ka (RL6007); Lrl1 (RL6053); Lrl7 (RL6008); Lr30 (RL6049); Lr10 (RL6004); Lr18 (RL6009); Lr21 (RL6043); Lr23 (RL6012); and Lr15 (RL6052). A Thatcher line (CI10003) with none of the above-mentioned $L r$ genes was included as a susceptible control in each inoculation experiment. Plants were inoculated by spraying with a spore suspension as previously described (16). Evaluation of the virulence phenotype was performed 12 to 14 days after inoculation. Infection types 0 to 2 were classified as avirulent. Infection types $2+$ to 3 were classified as virulent. Evaluation of the virulence of each isolate was performed at least three times to ensure that the phenotype was stable and reproducible.

RAPD-polymerase chain reaction conditions. DNA was extracted from germinating urediniospores as previously described (14) with the modification that 50 to $100 \mathrm{mg}$ of spores was used. RAPD-polymerase chain reaction (PCR) was performed with $12 \mathrm{ng}$ of DNA and $0.5 \mu \mathrm{l}$ of primer $(0.05 \mu \mathrm{g} / \mathrm{ml})$ using a thermocycler (MJ PCT-100; MJ Research Inc., Watertown, MA). The program conditions were $94^{\circ} \mathrm{C}$ for 2 min and then 40 cycles of $94^{\circ} \mathrm{C}$ for $1 \mathrm{~min}, 36^{\circ} \mathrm{C}$ for $1 \mathrm{~min}$, and $72^{\circ} \mathrm{C}$ for $2 \mathrm{~min}$ followed by $72^{\circ} \mathrm{C}$ for $10 \mathrm{~min}$. A preliminary screen of four isolates was performed with 700 RAPD primers that were from Operon Technologies (OP) (Alameda, CA) or custom designed (CRL) as described by Kubelik and Szabo (14). A second screen of 30 isolates was conducted with 20 primers that were variable between the first four isolates. Six of the twenty primers that produced the highest number of variable bands among the 30 isolates were used to screen the entire collection of 60 isolates. The final six primers were OPAL-13, OPAN-7, OPT-4, OPAN-5, OPAH-10, and CRL4, which together produced 54 polymorphic amplification products. Each primer was used for amplification of two DNA preparations from each isolate, and the amplifications were performed three times with each primer to ensure that the amplification patterns were consistent. All 60 isolates were analyzed at the same time with each primer and only the major polymorphic amplification products that were repeated in all reactions were scored.
TABLE 1. Puccinia triticina isolates and their virulence phenotype and geographical origin

\begin{tabular}{|c|c|c|c|c|}
\hline Number & $\begin{array}{l}\text { Virulence } \\
\text { phenotype }^{\text {a }}\end{array}$ & $\operatorname{Lr} 26^{b}$ & $\begin{array}{c}\text { Date of } \\
\text { isolation }\end{array}$ & Origin $^{c}$ \\
\hline 1 & THBR & + & 1994 & Israel - North \\
\hline 2 & THBR & + & 1994 & Israel - North \\
\hline 3 & THDR & + & 1994 & Israel - North \\
\hline 4 & CCDR & + & 1995 & Israel - Center \\
\hline 5 & MHBR & + & 1993 & Israel - North \\
\hline 6 & THBR & + & 1994 & Israel - North \\
\hline 7 & THBR & + & 1994 & Israel - South \\
\hline 8 & THBR & + & 1997 & Israel - North \\
\hline 9 & CCDR & + & 1997 & Israel - Center \\
\hline 10 & THBR & + & 1995 & Israel - North \\
\hline 11 & THBR & - & 1997 & Israel - South \\
\hline 12 & MGBR & - & 1994 & Israel - South \\
\hline 13 & PGMM & - & 1994 & Israel - North \\
\hline 14 & PGBR & - & 1995 & Israel - North \\
\hline 15 & PGMR & - & 1994 & Israel - South \\
\hline 16 & TGMR+15 & - & 1995 & Israel - North \\
\hline 17 & BBDM & - & 1995 & Israel - North \\
\hline 18 & PGMS & - & 1995 & Israel - North \\
\hline 19 & TGMR & - & 1997 & Israel - North \\
\hline 20 & PGMQ & - & 1997 & Israel - North \\
\hline 21 & MHRR+15 & + & 1995 & U.S. - California \\
\hline 22 & TFRR+15 & + & $\ldots$ & U.S. - Unknown \\
\hline 23 & TFCL & + & 1995 & U.S. - Oklahoma \\
\hline 24 & RFBL+15 & + & 1998 & U.S. - Texas \\
\hline 25 & TCBQ+15C & + & 1992 & U.S. - California \\
\hline 26 & CCRQ+15 & + & 1995 & U.S. - Indiana \\
\hline 27 & $\mathrm{KCBR}+15$ & + & 1995 & U.S. - Indiana \\
\hline 28 & MCBL+15 & + & 1990 & U.S. - Indiana \\
\hline 29 & CCPR & - & & U.S. - Unknown \\
\hline 30 & $\mathrm{CBBM}+15$ & - & 1994 & U.S. - Texas \\
\hline 31 & TLGH+15 & - & $\ldots$ & U.S. - Unknown \\
\hline 32 & MBMK+15 & - & & U.S. - Unknown \\
\hline 33 & JBBM & - & 1994 & U.S. - Oklahoma \\
\hline 34 & TBNQ+15 & - & 1998 & U.S. - Texas \\
\hline 35 & MBRR+15 & - & 1998 & U.S. - Texas \\
\hline 36 & KDGR+15 & - & 1992 & U.S. - Oklahoma \\
\hline 37 & LBBL & - & 1984 & U.S. - California \\
\hline 38 & MGBR+15 & - & 1995 & U.S. - Texas \\
\hline 39 & MCMR & + & $\ldots$ & Czech Republic \\
\hline 40 & KHPG+15 & + & $\ldots$ & Czech Republic \\
\hline 41 & $\mathrm{CHPQ}+15 \mathrm{~F}$ & + & $\ldots$ & Czech Republic \\
\hline 42 & FHPQ+15 & + & $\ldots$ & Czech Republic \\
\hline 43 & THPQ+15 & + & $\ldots$ & Czech Republic \\
\hline 44 & FHPH+15 & + & $\ldots$ & Czech Republic \\
\hline 45 & FHMQ+15 & + & $\ldots$ & Czech Republic \\
\hline 46 & THRR+15 & + & 1996 & Germany \\
\hline 47 & CCDR & + & 1996 & Germany \\
\hline 48 & CCDR & + & $\ldots$ & Germany \\
\hline 49 & SCJG+15 & + & 1997 & Germany \\
\hline 50 & SCJG+15 & + & 1997 & Germany \\
\hline 51 & $\mathrm{SCFB}+15$ & + & $\ldots$ & Germany \\
\hline 52 & SCPD+15 & + & $\ldots$ & Germany \\
\hline 53 & THMR+15 & + & 1992 & Poland \\
\hline 54 & THFR & + & $\ldots$ & Hungary \\
\hline 55 & DBBK & - & 1996 & Switzerland \\
\hline 56 & DGGG & - & 1996 & Switzerland \\
\hline 57 & FNMQ & - & 1996 & Switzerland \\
\hline 58 & FGMQ & - & 1996 & Switzerland \\
\hline 59 & DGBQ & - & 1996 & Switzerland \\
\hline 60 & JBGG & - & 1996 & Switzerland \\
\hline
\end{tabular}

${ }^{a}$ The virulence phenotypes are described with the P. triticina nomenclature (15).

${ }^{\mathrm{b}}$ Isolates virulent on $\operatorname{Lr} 26$ are marked by $(+)$ and avirulent isolates are marked by (-).

${ }^{\mathrm{c}}$ Isolates were provided by the following cooperators: U.S. - D. Long, The Cereal Disease Laboratory in St. Paul, MN; Switzerland - G. Schachermayr, Department of Resistance and Quality Breeding, SFR, Zurich; Central Europe (Germany, Czech Republic, Romania, and Poland) - U. Walther, Federal Center for Breeding, Aschersliben, Germany, A. Dreiseitl, Agricultural Research Institute, Kromeriz, the Czech Republic, M. Ittu, Research Institute for Cereals and Industrial Crops, Calarasi, Romania. Israeli isolates were from 1993 to 1996 virulence surveys. 
Data analysis. Data analyses were performed as follows. The impact of the geographical origin of the isolates was analyzed by comparing the isolates from Israel with isolates from Europe and from the United States. To test the relationships between Lr26 isolates, we compared the entire Lr26 $6^{+}$isolates with the rest of the isolates and with the entire population. Then, each of the three geographical groups (Israel, Europe, and the United States) was divided into two subgroups according to the virulence on $\operatorname{Lr} 26$ and the six subgroups were compared. Finally, a cluster analysis of all 60 isolates was performed and the obtained RAPD and virulence clusters were compared and analyzed.

Diversity analysis. Diversity and distance indices and their statistics were calculated from the virulence and RAPD patterns for all major groups, subgroups, and clusters. The virulence data included the isolate patterns on 16 differential lines without $\operatorname{Lr} 26$. The Lr26 virulence data were not considered because response on Lr26 was used as the grouping parameter and therefore the selection of Lr26 virulence types was not random. The RAPD data consisted of the isolate patterns that resulted from the 54 amplification products produced by the six primers that were mentioned previously. Bootstrapping across isolates was realized, and 50 random samples of 60 isolates (sampling with replacement) were drawn in each case. Dissimilarity between two isolates was calculated by the simple mismatch coefficient (29), defined as the normalized number of differentials (virulence markers) or amplification products (RAPD markers) on which the isolates responded differently. In addition, the Jaccard and the Dice coefficients (29) were used for analysis of RAPD data.

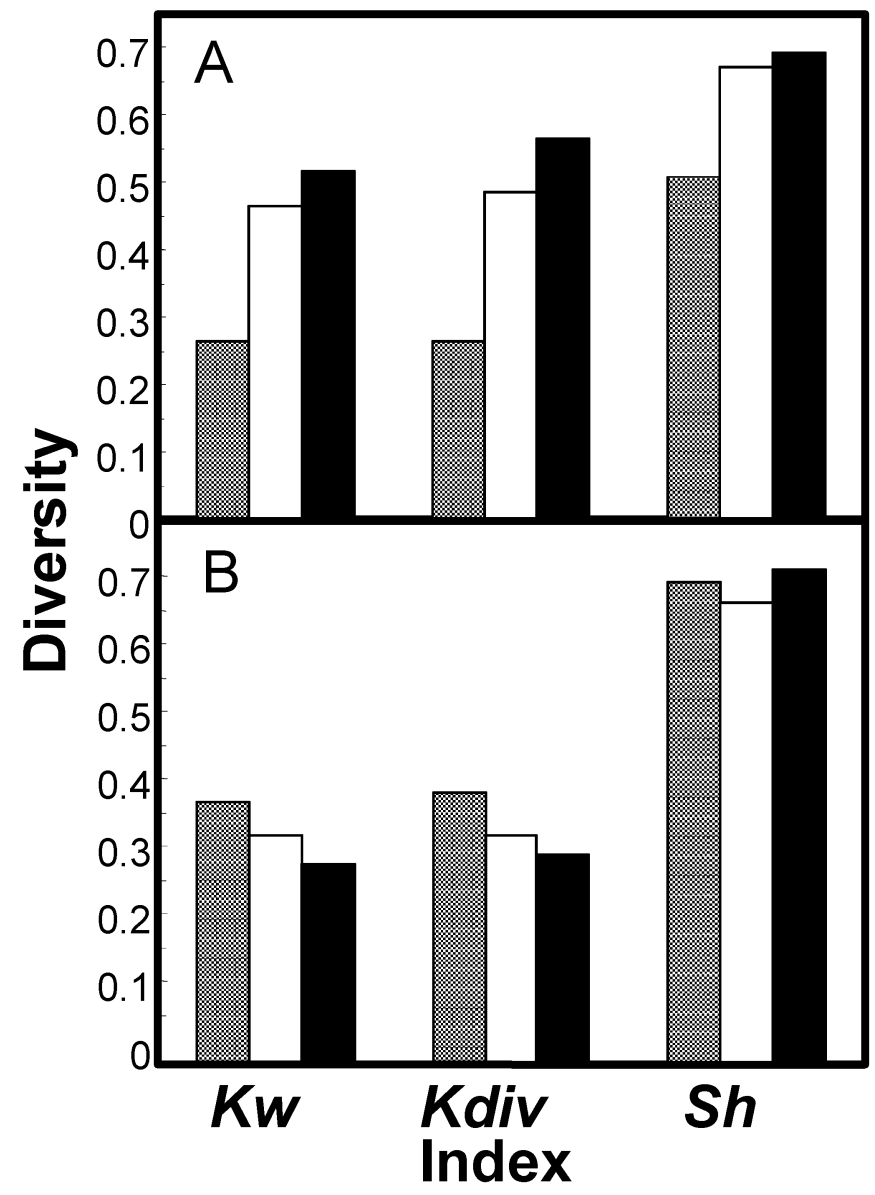

Fig. 1. Diversity within Puccinia triticina isolates from Israel, the United States, and Europe. The diversity within isolates from Israel (gray bars), the United States (white bars), and Europe (black bars) was calculated using Kosman's general $(K w)$ and genetic (Kdiv) diversity indices and Shannon's normalized index $(S h)$. A, Virulence markers; and $\mathbf{B}$, random amplified polymorphism DNA markers.
We used the Kosman's, Kb, (12,16) and Nei's, Nei, (22) distances to measure diversity between groups of isolates, and the Kosman's indices, $K w$ and Kdiv, $(12,16)$ and the normalized form of Shannon's entropy, Sh, (6) to estimate diversities within groups. All measures of diversity between and within populations were calculated by the KOIND software package (28). For interpretation of the data, we used the Kosman's indices because they were specifically designed for characterization of plant pathogen populations, which mainly reproduce asexually and therefore consist of clonal lineages $(12,16)$. All of the comparisons of diversities were between mean values for corresponding random samples of indices, which were calculated for each bootstrapped sample of isolates. Differences between these means, if stated, were statistically significant at $\alpha=0.05$ according to the Student's $t$ test.

Cluster analysis. Clustering was performed by the UPGMA dendrograms method (unweighted pair group arithmetic mean method) and by the matrix structuring technique (11). The dendrograms method is based on the principle of local optimality when the nearest items (isolates) are grouped. This may result in a situation that two or more items are placed very far from each other in the final dendrogram, although the actual distance between them may be relatively small, but not the smallest. In such a case, the dendrogram does not provide any evidence of proximity between the items, and closely related items might be placed on different branches of the dendrogram although they may belong to the same cluster. The matrix structuring technique is theoretically based on the principle of global optimality. The principle of this method is rearrangement of a given list of items (isolates) in a way that minimizes the sum of distances between consecutive items in an ordered list derived. In this case, the two nearest items with respect to distance are not necessarily the nearest neighbors in the obtained ordered list of items. Arrangement of items in a distance matrix according to the new order yields the structuring form of the matrix where the actual distance values are grouped and presented by symbols rather than by actual numbers. Clusters of similar items are produced according to the structuring form of the distance matrix $(11,13)$. However, any item that belongs to one group can theoretically be closely related to some items from a different group. Such proximity can be revealed by means of the structuring form of distance matrix, whereas in dendrograms, such proximity will be overlooked. The two methods complement each other and allow flexible decisions about cluster composition.

Clusters of isolates were constructed for virulence (on all 17 differential lines including $L r 26$ ) and RAPD markers. The UPGMA dendrograms were derived using NTSYSpc package, version 2.1 (Exeter Software, Setauket, NY). The similarity between all pairs of isolates was calculated according to the simple match coefficient for the virulence data, whereas in the case of RAPD data, three dendrograms based on the simple match, Jaccard and Dice coefficients were constructed. Only the dendrogram generated for the RAPD markers with respect to the simple match coefficient is presented. The cophenetic correlation was calculated to measure merit of fit for clustering by the dendrogram.

The matrix structuring technique with respect to the simple mismatch coefficient was realized for revealing clusters on the basis of the structured form of the distance matrix. Only the structured form of the distance matrix generated for the RAPD markers is presented.

Clusters were generated using findings of both the dendrogram and the matrix structuring methods. Homogeneity of isolates within groups was assessed by the Kosman measure of diversity within population $(K w)$ : low diversity means high homogeneity and vice versa. The Kosman distance $(K b)$ was used to measure groups' differentiation: two groups are more distinct if and only if the distance is greater. The expected clustering solution was supported by relatively high values of groups' homogeneity as well 
as by considerable difference between clusters. The corresponding estimates of diversities and distances were obtained as the average of bootstrap samples across isolates from the groups tested. Difference between estimates was declared if it was statistically significant at $\alpha=0.05$ according to the Student's $t$ test.

The Pearson correlation between virulence and RAPD differences of paired isolates was calculated to determine the relationship between virulence and RAPD phenotypes.

\section{RESULTS}

A total of 49 different virulence phenotypes were scored. Unique RAPD profiles were obtained for all isolates.

Diversity within and between groups. The virulence diversity among Israeli isolates was significantly lower than that of isolates from Europe and the United States (Fig. 1A). In contrast, the ge-

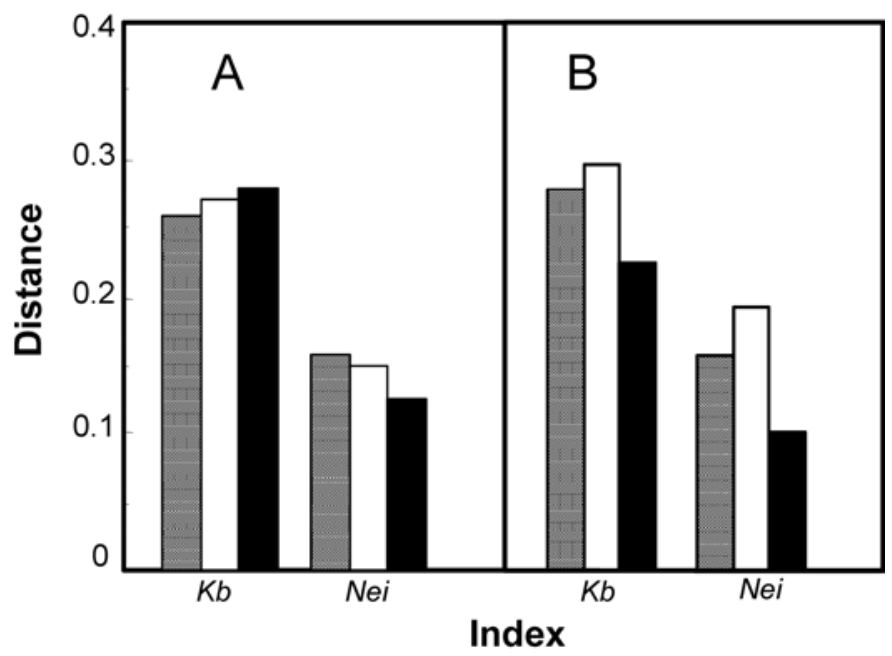

Fig. 2. Genetic distances between Puccinia triticina isolates from Israel, the United States, and Europe. The distances between $P$. triticina isolates from Israel and the United States (gray bars), Israel and Europe (white bars), and the United States and Europe (black bars) were calculated by Kosman's $(K b)$ and Nei's (Nei) indices. A, virulence markers; B, random amplified polymorphism DNA markers. netic diversity within the Israeli isolates as estimated by the RAPD data was similar to and even higher than the diversity within the European and U.S. isolates (Fig. 1B). These results suggest a greater uniformity of the virulence structure in the Israeli isolates than in the other isolates, but a similar level of genetic diversity, as estimated by the RAPD markers.

Distances between the different groups were evaluated according to the Kosman $(\mathrm{Kb})$ and $\mathrm{Nei}$ indices. Minor differences were observed in the distances between the different groups according to the virulence markers with opposite results obtained by the $\mathrm{Nei}$ and $K b$ indices (Fig. 2A). According to the RAPD markers, the largest distance was between Israeli and European isolates $(K b=$ $0.297, \mathrm{Nei}=0.192$ ), with both indices providing similar results (Fig. 2B). Although the differences in the distances between the Israeli isolates and the other two groups were statistically significant, these differences were relatively small. Therefore, it does not seem that the Israeli group is genetically more closely associated with one of the European or U.S. groups.

In order to test whether the Lr26 ${ }^{+}$isolates are genetically more related to each other than to randomly picked isolates, we compared the indices of diversity within and between $\mathrm{Lr}_{2} 6^{+}$and $\mathrm{Lr} 26^{-}$ subgroups. First, the total $\mathrm{Lr}^{2} 6^{+}$isolates were compared with the total $\mathrm{Lr}^{-} 6^{-}$isolates and with the general population. Then, the Lr26 ${ }^{+}$isolates from each of Israel, Europe, and the United States were analyzed and compared with the corresponding Lr26- isolates. The calculated diversity $(K w)$ within the entire collection of $\mathrm{Lr} 26^{+}$isolates was similar to the diversity within the entire population (0.418 and 0.417 , respectively, for the RAPD markers) and somewhat higher than the diversity within the $\mathrm{Lr}^{2} 6^{-}$isolates ( 0.418 versus 0.373$)$. According to the virulence markers, the diversity level of the Lr26- isolates from Israel, as measured by $K w$ and Kdiv, was about $60 \%$ greater than that of the $\mathrm{Lr}^{2} 6^{+}$isolates (Fig. 3A). Still, the diversity levels within the Israeli Lr26 $6^{+}$and Lr26- isolates were much lower than the diversity levels within any of the other subgroups, as was also found by analysis of the entire Israeli population (Fig. 1A). According to the RAPD markers, the diversity level within the $\operatorname{Lr} 26^{+}$isolates was always higher than that within the corresponding $\mathrm{Lr}^{2} 6^{-}$isolates (Fig. 3B). The diversity level within $\mathrm{Lr}^{2} 6^{+}$isolates from Israel was $64 \%$ greater than that within the Lr26- isolates in this group. Taken together, these results show that $\mathrm{Lr}^{-} 6^{+}$isolates are at least as genetically di-

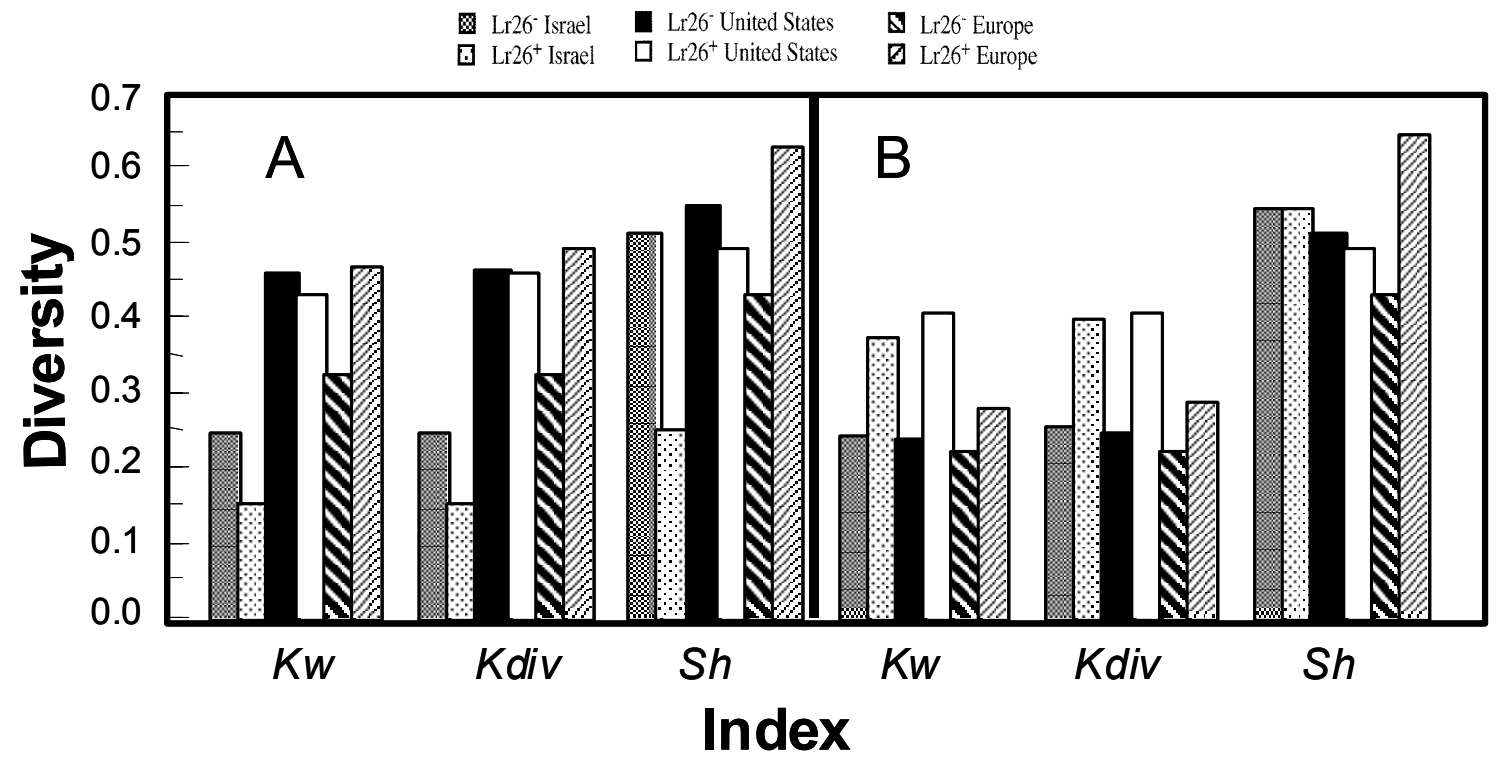

Fig. 3. Diversity within Lr26+ and Lr26- Puccinia triticina isolates. The isolates from Israel, the United States, and Europe were divided into subgroups according to their virulence on $\operatorname{Lr} 26$. Diversity levels within each subgroup were calculated for the A, virulence and $\mathbf{B}$, random amplified polymorphism DNA data: Lr26Israel, Lr26+ Israel, Lr26- United States, Lr26+ United States, Lr26- Europe, and Lr26 Europe. Kw and Kdiv are Kosman's general and genetic diversity indices, respectively. Sh is Shannon's normalized index. 
verse as the rest of the population. In contrast to the virulence data, the $\mathrm{Lr}^{2} 6^{+}$isolates from Israel had genetic diversity levels similar to or even higher than those of the corresponding isolates from Europe and the United States according to the RAPD data (Fig. 3). Comparison of Kosman distances $(K b)$ between all of the different Lr26 subgroups did not reveal any association between the Lr26 $6^{+}$subgroups according to both types of markers (data not shown). This means that the $\operatorname{Lr} 26^{+}$isolates from the different locations are as genetically distant as the rest of the isolates. The Israeli $\mathrm{Lr}^{+} 6^{+}$and $\mathrm{Lr}^{+} 6^{-}$groups were more genetically dissimilar than the total $\mathrm{Lr}^{2} 6^{+}$and $\mathrm{Lr} 26^{-}$isolates $(K b=0.239$ versus 0.190, respectively).

Comparison of the dissimilarity values between all possible pairs $(1,770)$ of all 60 isolates measured by the simple mismatch coefficient for the virulence and RAPD patterns revealed an in- significant correlation of 0.08 between the virulence and the RAPD markers.

Cluster analysis. Clusters were generated for both types of markers by the UPGMA dendrograms. The dendrogram produced for the virulence data on the basis of simple mismatch coefficient did not separate the population into distinct groups (data not shown). The RAPD dendrograms constructed for the simple match, the Jaccard, and the Dice coefficients of similarity were qualitatively similar, and only the dendrogram based on the simple match coefficient is presented (Fig. 4). Most isolates were clustered into one of four major groups. The majority of the isolates from Israel, including nine $\mathrm{Lr} 26^{-}$and six $\mathrm{Lr} 26^{+}$isolates, belong to the first cluster together with three isolates from the United States. The second and the third clusters consist of 11 isolates from the United States and 15 isolates from Europe, respec-

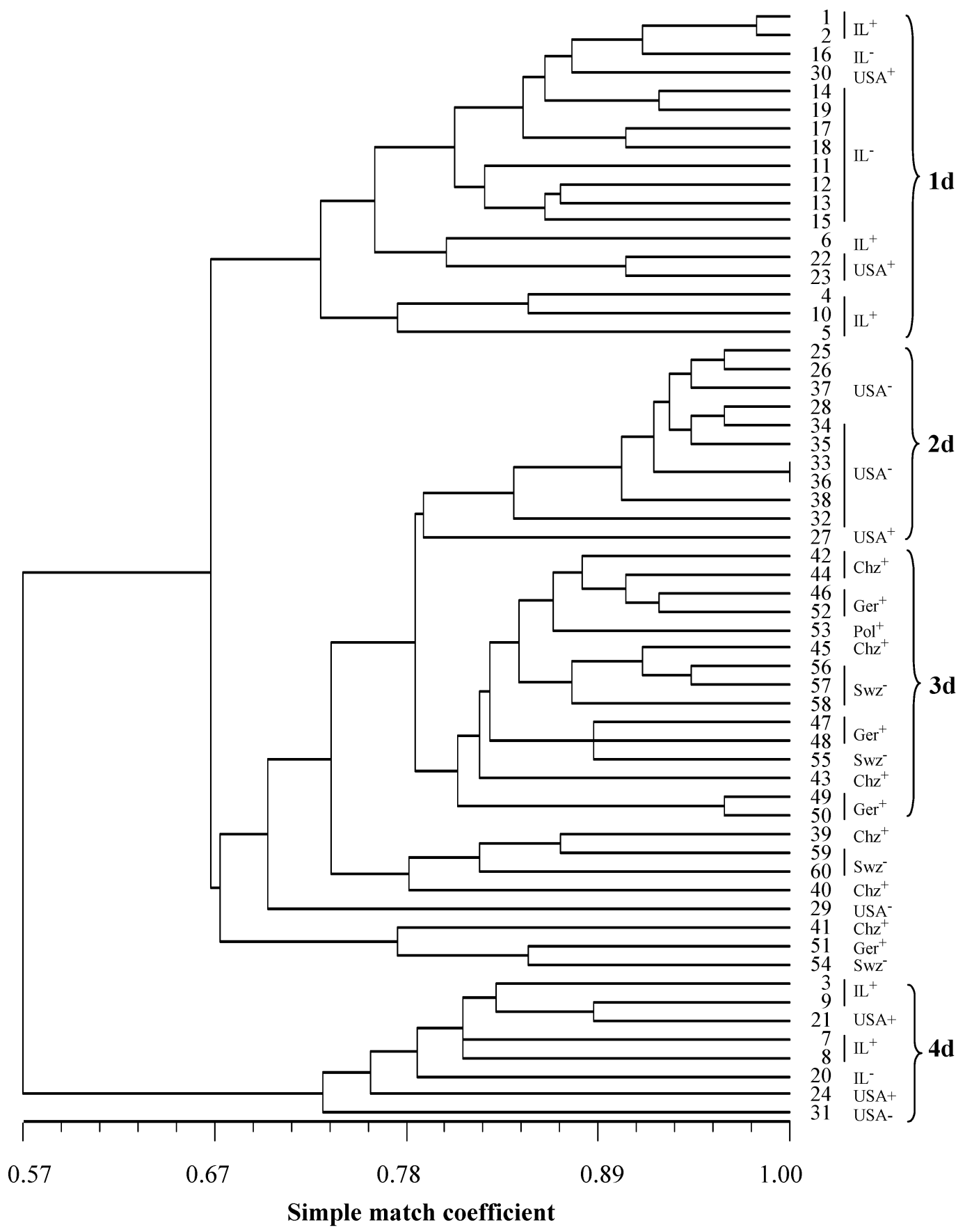

Fig. 4. Dendrogram of 60 Puccinia triticina isolates based on the random amplified polymorphism DNA data. The clusters were constructed using the unweighted pair-group method with arithmetic average dendrogram with respect to the simple match coefficient. The number, location, and Lr26 phenotype of each isolate are shown on the right. The isolates in each of the main clusters are boxed and the cluster numbers are indicated on the chart. 
tively. The fourth cluster includes five isolates from Israel and three isolates from the United States. A total of 52 isolates were included in one of the four clusters, and 8 isolates were not associated with any of the main groups. The dendrogram suggests geographically based separation of the majority of the isolates (groups 1 to 3) with sporadic distribution of the $\mathrm{Lr}^{+} 6^{+}$isolates among all four groups. The cophenetic correlation was good (0.82) but it was not high enough to make a confident clustering solution on the basis of this dendrogram.

The matrix structuring technique was used along with the dendrogram method to improve the clustering solution. The matrix of the simple mismatch dissimilarities between all pairs of the 60 isolates was transformed into the structured form. The clusters that were generated by the matrix structuring technique (Fig. 5, s-clusters) were similar to those obtained by the UPGMA dendrogram (Fig. 4, d-clusters) with a few exceptions. For example, iso- late 30 is clustered by both methods in the same group that includes mainly Israeli isolates (1d and 1s). However, the matrix structuring plot shows that this isolate is also similar to isolates $25,26,35$, and 38 , which are clustered in groups $2 \mathrm{~d}$ and $2 \mathrm{~s}$ in the dendrogram and in the matrix structuring plot, respectively. On the other hand, isolate 23 belongs to cluster $1 \mathrm{~d}$, but it shows close similarity to isolates $25,26,28,33,34,35,36$, and 37 , which are grouped in cluster $2 \mathrm{~d}$ in the dendrogram and cluster $2 \mathrm{~s}$ in the matrix structuring plot. The isolates were thus separated into new groups that did not include isolates that could be clustered into more than one main group. The four new groups were designated group A, which included only the 15 isolates from Israel, and groups $\mathrm{B}, \mathrm{C}$, and $\mathrm{D}$, which are identical to the original clusters $2 \mathrm{~d}, 3 \mathrm{~d}$, and $4 \mathrm{~d}$, respectively. A total of 49 isolates, including all of the isolates from Israel, 16 isolates from the United States, and 13 isolates from Europe, were represented in these groups.

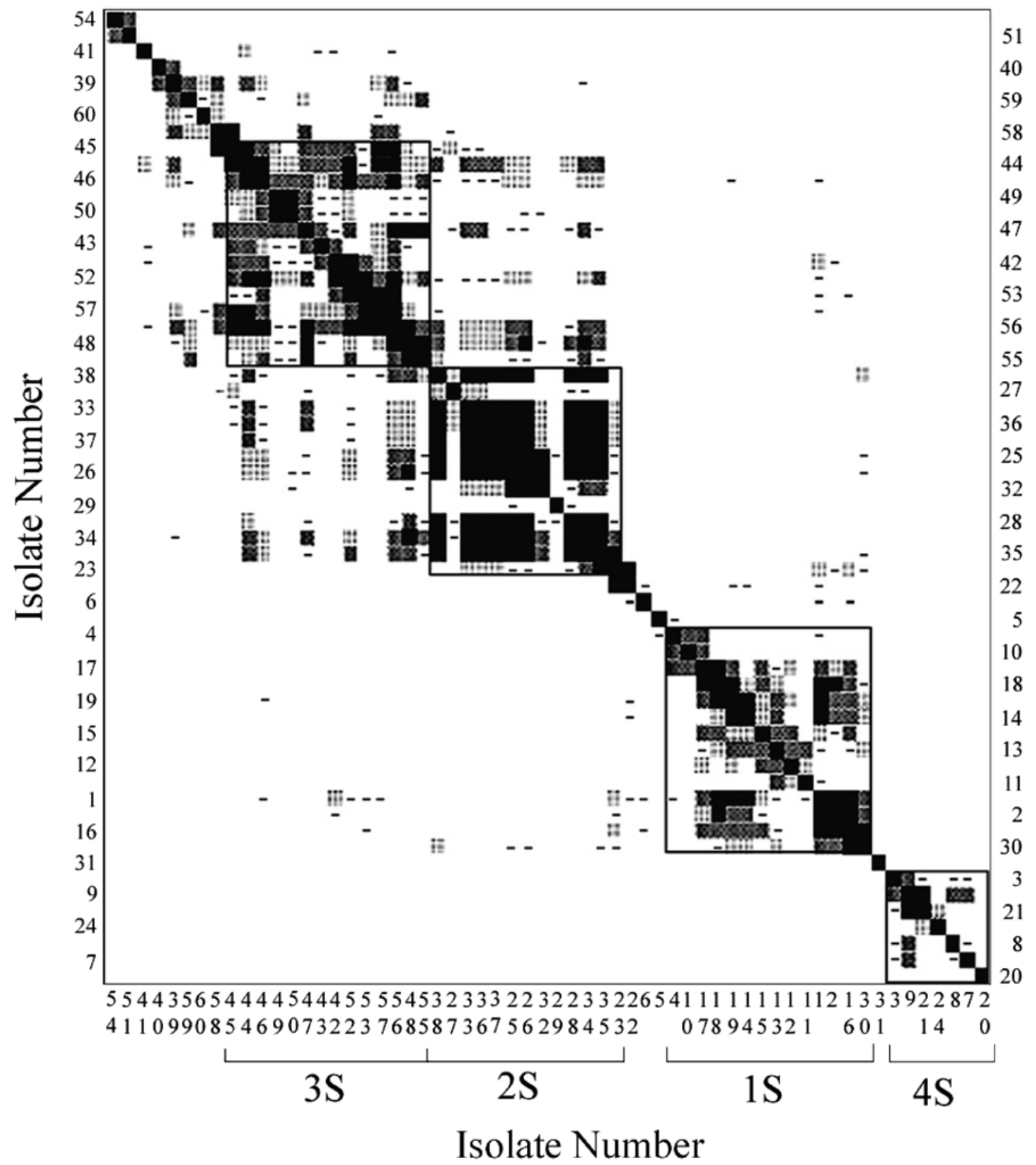

Fig. 5. Structured form of the random amplified polymorphism DNA matrix of distances between all pairs of 60 Puccinia triticina isolates. Distances are represented as follows: 0 to 0.13 , 0.13 to 0.17 , 0.17 to 0.19 , and -0.19 to 0.21 . Blank represents distances that are greater than 0.21 . The isolates in each of the main clusters are boxed and the cluster numbers are indicated on the chart. 
The homogeneity of isolates within the four clusters (A, B, C, and $\mathrm{D}$ ) and the distances between the clusters confirmed that the isolates in each cluster indeed form a distinct genetic group. The diversity $(K w)$ according to the RAPD markers within the groups was relatively low and ranged from 0.127 to 0.260 (data not shown), indicating a relative homogeneity of the clusters. According to the virulence data, group $\mathrm{D}$ was closer to groups $\mathrm{A}$ and $\mathrm{B}$ $(K b=0.150$ and 0.237 , respectively) than to group $\mathrm{C}(K b=$ 0.269 ), whereas the distances of group $C$ from the other three groups were almost equal (Table 2). According to the RAPD data, the distances between group D and any of the other three groups were considerably higher than the distances among A, B, and C (Table 2). These results suggest that the Israeli isolates may represent two different genetic sources, because group D contains several isolates from Israel that are highly distant from group A, which contains the rest of the Israeli isolates.

\section{DISCUSSION}

The diversity levels within groups of $P$. triticina isolates as measured by virulence and RAPD markers were of opposite order. For virulence, much lower diversity was found in the Israeli isolates compared with that of isolates from Europe and the United States (Fig. 1A), whereas for the RAPD data, the Israeli isolates had the highest diversity (Fig. 1B). This result suggests that the two types of markers represent different sources of diversity that contribute to the structure of the examined populations. A major reason for the observed differences may be the influence of the host on the composition of pathogen populations $(9,10,24)$. The virulence phenotypes are far more sensitive to host selection than the RAPD markers, since the frequency of the virulence genes in rust populations is theoretically directly influenced by the spectrum of resistance genes in the wheat on which the population propagates. A selection pressure is imposed by the wheat cultivars that are grown in the region from which the rust isolates arrive (source region). Only genotypes with a combination of virulence genes that can propagate on the wheat genotypes in the source region will be represented in the destination region. The high level of Lr26+ isolates in the Israeli rust population suggests that they may originate from isolates that arrive from regions in which $L r 26$ wheat cultivars are grown on a large scale. Additionally, the frequency of the different virulence genes in the new population is also influenced by the wheat cultivars that are grown in this area. Therefore, pathotype distribution in this population may be different than that in the source population. These processes may result in relatively low virulence diversity within the new population, especially in populations from small geographical regions where only certain wheat cultivars with a very limited number of $L r$ gene combinations are used. This phenomenon may be reflected in our results by the low virulence diversity within the Israeli isolates compared with that of U.S. and European isolates that represent much wider geographical re- gions. The Israeli rust population has a high level of $\mathrm{Lr}^{2} 6^{+}$pathotypes, although $\operatorname{Lr} 26$ wheat is not grown in this region. This suggests that there is no counter selection against the $\operatorname{Lr} 26^{+}$ pathotypes and is consistent with the current paradigm according to which the rust population in Israel is renewed annually by migrating spores and therefore the pathotype composition does not match the $L r$-gene combination in the local wheat population.

RAPD and other genomic markers that are not directly influenced by the host resistance genes are much less affected by host selection and therefore may represent more accurately the genetic diversity within an examined population $(2,18)$. The diversity within the Israeli isolates was the highest according to the RAPD data, and overall diversities within the three groups were of relatively moderate range according to the $K w$ index (Fig. 1B). This result suggests that despite the relatively low level of virulence diversity, the genetic diversity within the Israeli rust isolates is similar to or even higher than that found in groups of rust isolates collected from considerably wider territories in Europe and the United States.

According to the virulence data, the differences in distances between the three groups were of relatively small range, whereas according to the RAPD markers, the distances between the Israeli and the other isolates were similar to and even higher than the distance between the European and the U.S. isolates (Fig. 2). These data do not support an exchange of isolates between Israel and Europe, unlike the current distribution zones that categorize part of East Europe and the Middle East in the same epidemiological zone of $P$. triticina $(17,31)$. These differences may be attributed to the differences between the virulence (which is the basis for the current separation into epidemiological zones) and the molecular data that we used in this work.

A major objective of this study was to determine whether isolates of $P$. triticina that are virulent on wheat with the Lr26 resistance gene have a common genetic origin or, rather, if they result from multiple events that occurred independently in different places and times. Comparison of the diversity within the $\mathrm{Lr} 26^{+}$ isolates with the diversity within the $\mathrm{Lr}^{2} 6^{-}$isolates and within the entire isolate collection showed that the $\mathrm{Lr}^{2} 6^{+}$isolates were as diverse as the rest of the population. This result suggested that the Lr26 $6^{+}$isolates from different places are not more closely related to each other than other isolates and therefore may have originated from different genetic backgrounds. To further test this hypothesis, each of the three major groups (from Israel, Europe, and the United States) was divided into Lr26 $6^{+}$and $\mathrm{Lr}^{2} 6^{-}$subgroups and the diversity within and between these subgroups was analyzed. As with the general populations, the lowest genetic diversity according to the virulence markers was among the Israeli subgroups (Fig. 3A), whereas according to the RAPD data, the Israeli subgroups had a genetic diversity similar to that of the other subgroups (Fig. 3B). The Lr26+ isolates from all three locations had a genetic diversity similar to and even higher than that of the corresponding $\mathrm{Lr}^{-} 6^{-}$isolates (Fig. 3B). Moreover, there

TABLE 2. Genetic distances between the clusters of Puccinia triticina isolates virulent or avirulent on Lr26 and collected from different regions of the world

\begin{tabular}{|c|c|c|c|c|c|c|c|}
\hline \multirow[b]{2}{*}{ Cluster $^{\mathrm{a}}$} & \multirow[b]{2}{*}{ Marker } & \multicolumn{2}{|c|}{ B } & \multicolumn{2}{|c|}{$\mathrm{C}$} & \multicolumn{2}{|c|}{$\mathrm{D}$} \\
\hline & & $K b^{\mathrm{b}}$ & $N e i^{\mathrm{c}}$ & $K b$ & $\mathrm{Nei}$ & $K b$ & $\mathrm{Nei}$ \\
\hline A & $\begin{array}{l}\text { Virulence } \\
\text { RAPD }\end{array}$ & $\begin{array}{l}0.263 \\
0.313\end{array}$ & $\begin{array}{l}0.164 \\
0.261\end{array}$ & $\begin{array}{l}0.262 \\
0.285\end{array}$ & $\begin{array}{l}0.148 \\
0.203\end{array}$ & $\begin{array}{l}0.150 \\
0.356\end{array}$ & $\begin{array}{l}0.034 \\
0.287\end{array}$ \\
\hline B & $\begin{array}{l}\text { Virulence } \\
\text { RAPD }\end{array}$ & $\begin{array}{l}\ldots \\
\ldots\end{array}$ & $\begin{array}{l}\ldots \\
\ldots\end{array}$ & $\begin{array}{l}0.286 \\
0.181\end{array}$ & $\begin{array}{l}0.113 \\
0.105\end{array}$ & $\begin{array}{l}0.237 \\
0.460\end{array}$ & $\begin{array}{l}0.095 \\
0.496\end{array}$ \\
\hline $\mathrm{C}$ & $\begin{array}{l}\text { Virulence } \\
\text { RAPD }\end{array}$ & $\begin{array}{l}\ldots \\
\ldots\end{array}$ & $\begin{array}{l}\cdots \\
\ldots\end{array}$ & $\begin{array}{l}\ldots \\
\ldots\end{array}$ & $\begin{array}{l}\ldots \\
\ldots\end{array}$ & $\begin{array}{l}0.269 \\
0.447\end{array}$ & $\begin{array}{l}0.122 \\
0.459\end{array}$ \\
\hline
\end{tabular}

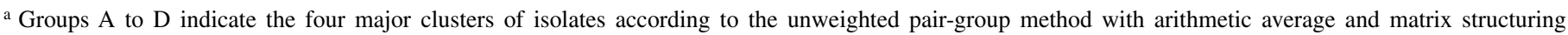
technique methods. Groups A, B, and C include isolates from Israel, the United States, and Europe, respectively, and group D includes isolates from Israel and the United States.

${ }^{\mathrm{b}} \mathrm{Kb}=$ Kosman distance.

c $N e i=$ Nei distance. 
was no specific association between the $\mathrm{Lr}^{2} 6^{+}$isolates from the different regions as indicated by the calculated distances (data not shown). These results exclude the possibility that the $\mathrm{Lr}^{2} 6^{+}$isolates represent a homogeneous group and imply that $\mathrm{Lr}^{2} 6^{+}$isolates developed independently in different places. According to our results, isolates with the ability to overcome the Lr26 resistance gene may have existed at low frequencies in rust populations around the world even before the introduction of the $\operatorname{Lr} 26$ gene into cultivated wheat, and their frequencies in the population increased following the introduction and large-scale planting of wheat cultivars with the Lr26 gene.

Interpretation of the data in this study is based on the results obtained by the Kosman's indices ( $K w$ and $K b$ ), which have been developed for analysis of mainly asexually reproducing plant pathogen populations $(12,16)$. The commonly used genetic diversity indices take into account frequencies of individual characters (virulence and amplification products, etc.) with no respect to phenotypes, whereas the phenotypic diversity indices are based on the frequencies of phenotypes regardless of how many individual factors these phenotypes share. The Kosman's indices $K w$ and $K b$ take into account both the phenotypic structure of populations and the degrees of similarity among distinct phenotypes. There was a general agreement between the Kosman's genetic diversity index $(K d i v)$ and the major diversity index $(K w)$, although minor differences were revealed in some cases. The differences between the $K w$ and the Shannon normalized $(S h)$ indices were much greater and opposite results were obtained in a few cases. For example, according to the RAPD data, the diversity level within the Israeli $\mathrm{Lr}^{2} 6^{+}$isolates, as evaluated by the $S h$ index, was significantly greater than the diversity within U.S. Lr26+ isolates, while opposite relationships were obtained with the $K w$ index (Fig. 3B). Differences also were found between the $K b$ and the $N e i$ indices (for example, the virulence data in Fig. 2A). The results of this study support previous observations about the accuracy of the Kosman's indices for measurement of diversity within and between populations of plant pathogens with respect to other indices $(12,16)$. It is therefore recommended that the genetic or the phenotypic diversity indices together with the Kosman's indices of diversity be used to analyze populations of plant pathogens.

Cluster analysis was performed by the UPGMA dendrograms method and by the matrix structuring technique (11). The structure of the UPGMA dendrograms depends on the measure of similarity or dissimilarity between individuals, and in general, different indices may produce distinct results of isolate grouping. The simple mismatch coefficient is suitable and usually used for measuring dissimilarity between isolates in the case of virulence data. On the other hand, there is no general agreement concerning the suitable measure of similarity or dissimilarity between isolates in the case of molecular markers. For example, the simple match, the Jaccard, and the Dice coefficients were used for analysis of RAPD data $(19,20)$. Therefore, for confidence, we constructed the UPGMA dendrograms for all three indices of similarity in the case of RAPD patterns. The resulting three dendrograms were qualitatively similar, and therefore, we presented and considered only the UPGMA dendrogram based on the simple match coefficient (Fig. 4). Clusters of the isolates were generated for both types of markers, but well-defined clusters were generated only with the RAPD markers, while the virulence data produced many small, heterogeneous groups (data not shown). According to the RAPD data, the clusters produced by the dendrogram separated the isolates into four major groups. In the first cluster, most isolates were from Israel, whereas the second and the third clusters included isolates from the United States and Europe, respectively (Fig. 4). The last cluster included five isolates from different regions in Israel and three isolates from the United States. The structured form of the distance matrix provided a similar separation (Fig. 5). However, it showed that isolates 22, 23, and 30 (from the United States), placed in cluster 1d in the UPGMA den- drogram (Fig. 4), are also closely related to isolates from group $2 \mathrm{~d}$. These isolates were therefore omitted from cluster $1 \mathrm{~d}$, resulting in a new group (group A) that includes only the 15 isolates from Israel. Groups B, C, and D are identical to the original clusters $2 \mathrm{~d}, 3 \mathrm{~d}$, and $4 \mathrm{~d}$, respectively. Groups A, B, and C, which contained isolates from Israel, the United States, and Europe, respectively, were characterized by low diversity levels (data not shown) compared with that of the corresponding original groups (Fig. 1). Group D was also characterized by relatively low diversity level $(K w=0.249)$, but it was distant from the rest of the groups according to the RAPD data (Table 2). Thus, the isolates in group $\mathrm{D}$ form a distinct cluster and are probably derived from a separate genetic background than the rest of the isolates, including the Israeli isolates from group A. The virulence data did not distinguish between the isolates of group D and the other groups with respect to the diversity between the groups (Table 2). Based on these results, it is argued that the rust populations in Israel may represent at least two separate genetic sources and possibly also different geographical sources. The regions from which rust arrives in Israel are still unknown but the current study does not support Europe as a major source. Considering the wheat growing seasons and the wind patterns, one possibility may be that isolates arrive in Israel from Africa and are then transmitted in the north or northeast. This hypothesis might be tested by comparison of the Israeli isolates with rust isolates, e.g., from Kenya, Egypt, Turkey, Russia, or Iran.

The findings of this study suggest that the $\operatorname{Lr} 26^{+}$phenotype is not a new trait of $P$. triticina in Israel and did not evolve as a result of the introduction of wheat cultivars with the Lr26 resistance gene. On the other hand, the appearance of large populations of Lr26 $6^{+}$pathotypes is probably due to large-scale introduction of wheat cultivars that carry the $\operatorname{Lr} 26$ resistance gene in other regions. The advantage of the molecular markers over the virulence phenotypic markers for assessment of genetic diversity in populations of plant pathogens has been demonstrated in previous studies $(3,10,18)$. Our results further emphasize the differences between molecular and phenotypic markers. The utility of the virulence markers is mainly for assessment of host influence and for determination of heterogeneity levels in the population. However, these markers are less appropriate for estimation of genetic diversity levels because the frequencies of the virulence genes are strongly influenced by regional factors and therefore do not reflect the overall genetic potential in a given population.

\section{ACKNOWLEDGMENTS}

We thank the various cooperators for supplying rust isolates and I. Lavian for greenhouse assistance. E. Kosman was supported by the Colton Foundation of Tel Aviv University. This work was supported in part by the Leiberman-Okinow Foundation.

\section{LITERATURE CITED}

1. Anikster, Y., Bushnell, W. R., Eilam, T., Manisterski, J., and Roelfs, A. P. 1997. Puccinia recondita causing leaf rust on cultivated wheat and rye. Can. J. Bot. 75:2082-2096.

2. Berg, D. E., Akopyants, N. S., and Kersulyte, D. 1994. Fingerprinting microbial genomes using the RAPD or AP-PCR method. Methods Mol. Cell. Biol. 5:13-24.

3. Chen, X., Line, R.F., and Leung, H. 1995. Virulence and polymorphic DNA relationships of Puccinia striiformis f. sp. hordei to other rusts. Phytopathology 85:1335-1342.

4. Danial, D. L., Stubbs, R. W., and Parlevliet, J. E. 1994. Evolution of virulence patterns in yellow rust races and its implications for breeding fro resistance in wheat in Kenya. Euphytica 80:165-170.

5. Dinoor, A., Eshed, N., Ecker, R., Gerechter-Amitai, Z., Solel, Z., Manisterski, J., and Anikster, Y. 1991. Fungal diseases of wild tetraploid wheat in a natural stand in northern Israel. Israel J. Bot. 40:481500 .

6. Goodwin, S. B. 1997. The population genetics of Phytophthora. Phytopathology $87: 462-473$ 
7. Hsam, S. L. K., Mohler, V., Hartl, L., Wenzel, G., and Zeller, F. J. 2000. Mapping of powdery mildew and leaf rust resistance genes on the wheatrye translocation chromosome T1BL-1RS using molecular and biochemical markers. Plant Breed. 119:87-89.

8. Kolmer, J. A. 1991. Evolution of distinct populations of Puccinia recondita f. sp. tritici in Canada. Phytopathology 81:316-322.

9. Kolmer, J. A. 1996. Genetics of resistance to wheat leaf rust. Annu. Rev. Phytopathol. 34:435-455.

10. Kolmer, J. A., Liu, J. Q., and Sies, M. 1995. Virulence and molecular polymorphism in Puccinia recondita f. sp. tritici in Canada. Phytopathology 85:276-285.

11. Kosman, E. 1990. Structuring of matrices. Sov. Math. Dokl. 41:152-155.

12. Kosman, E. 1996. Differences and diversity of plant pathogen populations: A new approach for measuring. Phytopathology 86:1152-1155.

13. Kosman, E., Eshel, A., and Weisel, Y. 1997. The "traveling salesman problem": A new approach for identification of differences among pollen allergens. Intern. Arch. All. Immunol. 112:371-377.

14. Kubelik, A. R., and Szabo, L. J. 1995. High-GC primers are useful in RAPD analysis of fungi. Curr. Genet. 28:384-389.

15. Long, D., and Kolmer, J. A. 1989. North American system of nomenclature for Puccinia recondita f. sp. tritici. Phytopathology 79:525-529.

16. Manisterski, J., Eyal, Z., Ben-Yehuda, P., and Kosman, E. 2000. Comparative analysis of indices in the study of virulence diversity between and within populations of Puccinia recondita f. sp. tritici in Israel. Phytopathology 90:601-607.

17. McIntosh, R. A., Welling, C. R., and Park, R. F. 1996. Wheat Rust: An Atlas of Resistance Genes. CSIRO Publishing, Australia.

18. Michelmore, R. W., and Hulbert, S. H. 1987. Molecular markers for genetic analysis of phytopathogenic fungi. Annu. Rev. Phytopathol. 25:383404.

19. Munaut, F., Hamaide, N., and Maraite, H. 2002. Genomic and pathogenic diversity in Colletotrichum gloeosporioides from wild native
Mexican Stylosanthes spp., and taxonomic implications. Mycol. Res. 106:579-593.

20. Muñoz, G., Hinrichsen, P., Brygoo, Y., and Giraud, T. 2002. Genetic characterization of Botrytis cinerea populations in Chile. Mycol. Res. 106:594-601.

21. Narajan, S. 1990. Long distance dispersion of rust pathogens. Annu. Rev. Phytopathol. 28:139-153.

22. Nei, M. 1972. Genetic distance between populations. Am. Nat. 106:283292.

23. Park, R. F., and Felsenstein, F. G. 1998. Physiological specialization and pathotype distribution. Plant Pathol. 47:157-164.

24. Park, R. F., Goyeau, H., Felsenstein, F. G., Bartos, P., and Zeller, F. J. 2001. Regional phenotypic diversity of Puccinia triticina and wheat host resistance in western Europe. Euphytica 122:113-127.

25. Saari, E. E., and Prescott, J. M. 1985. World distribution in relation to economic losses. Pages 259-298 in: The Cereal Rusts. A. Roelfs and W. Bushnell, eds. Academic Press, Orlando.

26. Samborski, D. J., and Dyck, P. L. 1976. Inheritance of virulence in Puccinia recondita on six back cross lines of wheat with single genes for resistance to leaf rust. Can. J. Bot. 54:1666-1671.

27. Sawhney, R. N., and Sharma, J. B. 1999. Novel complementary genes for adult plant leaf rust resistance in a wheat stock carrying the 1BL-1RS translocation. Plant Breed. 118:269-271.

28. Schachtel, G. A., and Kosman, E. 2002. KOIND package. Online Publication, http://www.va-tipp.de. Biometrie und Populations Genetik, JustusLiebig Universitat, Giessen.

29. Sneath, P. A., and Sokal, R. R. 1973. Numerical Taxonomy. W. H. Freeman \& Co., San Francisco.

30. Statler, G. 1985. Mutations affecting virulence in Puccinia recondita. Phytopathology 75:565-567.

31. Zadoks, J. C. 1965. Epidemiology of wheat rusts in Europe. FAO Plant Prot. Bull. 13:97-108. 